\title{
Publisher Correction: Experimental identification of non-classicality of noisy twin beams and other related two-mode states
}

levgen I. Arkhipov \& Jan Peřina Jr.

Correction to: Scientific Reports https://doi.org/10.1038/s41598-018-19634-1, published online 23 January 2018

The previous version of this Article contained errors in the Introduction under the subheading 'Twin beam and its transformation on a beam splitter',

$\lambda=\left(1, \lambda_{1}, \lambda_{2}, \lambda_{1} \lambda_{2}\right)^{\mathrm{T}}$

now reads:

$\lambda \equiv\left(1, \lambda_{1}, \lambda_{2}, \lambda_{1} \lambda_{2}\right)^{\mathrm{T}}$

Additionally, the Publisher Correction published on $30^{\text {th }}$ April 2018 contains errors.

"This Article contains errors in Equation 18.

$\mathrm{G}_{\mathcal{N}}\left(\lambda_{1}, \lambda_{1}\right)=\frac{1}{\left[\lambda^{\mathrm{T}} \mathbf{K} \lambda\right]^{1 / 2}}$

and $\lambda \equiv\left(1, \lambda_{1}, \lambda_{2}, \lambda_{1}, \lambda_{2},\right)^{\mathrm{T}}$.

should read:

$\mathrm{G}_{\mathcal{N}}\left(\lambda_{1}, \lambda_{1}\right)=\frac{1}{\left[\lambda^{\mathrm{T}} \mathbf{K} \lambda\right]^{1 / 2}}$

and $\lambda \equiv\left(1, \lambda_{1}, \lambda_{2}, \lambda_{1} \lambda_{2}\right)^{\mathrm{T}}$ "

should read:

"The original version of this Article contained errors in Equation 18.

$\mathrm{G}_{\mathcal{N}}\left(\lambda_{1}, \lambda_{2}\right)=\frac{1}{\left[\lambda^{\mathrm{T}} \mathrm{K \lambda}\right]^{1 / 2}}$

and $\boldsymbol{\lambda}=\left(1, \lambda_{1}, \lambda_{2}, \lambda_{1}, \lambda_{2},\right)^{\mathrm{T}}$.

now reads:

$\mathrm{G}_{\mathcal{N}}\left(\lambda_{1}, \lambda_{2}\right)=\frac{1}{\left[\lambda^{\mathrm{T}} \mathbf{K} \lambda\right]^{1 / 2}}$

and $\boldsymbol{\lambda} \equiv\left(1, \lambda_{1}, \lambda_{2}, \lambda_{1} \lambda_{2}\right)^{\mathrm{T}}$ "

RCPTM, Joint Laboratory of Optics of Palacký University and Institute of Physics of CAS, Faculty of Science, Palacký University, 17.listopadu 12, 771 46, Olomouc, Czech Republic. Correspondence and requests for materials should be addressed to I.I.A. (email: ievgen.arkhipov@gmail.com) 
(i) Open Access This article is licensed under a Creative Commons Attribution 4.0 International License, which permits use, sharing, adaptation, distribution and reproduction in any medium or format, as long as you give appropriate credit to the original author(s) and the source, provide a link to the Creative Commons license, and indicate if changes were made. The images or other third party material in this article are included in the article's Creative Commons license, unless indicated otherwise in a credit line to the material. If material is not included in the article's Creative Commons license and your intended use is not permitted by statutory regulation or exceeds the permitted use, you will need to obtain permission directly from the copyright holder. To view a copy of this license, visit http://creativecommons.org/licenses/by/4.0/.

(C) The Author(s) 2018 